\title{
CÔNG TÁC XÂY DỰNG CHƯƠNG TRÌNH ĐÀO TẠO ĐẠI HỌC TẠI TRƯỜNG ĐẠI HỌC THỦ DẦU MỘT
}

\author{
Lê Thị Kim Út $t^{(*)}$, Nguyễn Thị Vinh ${ }^{(*)}$
}

(*) Thạc sĩ. Truoòng Đại học Thủ Dầu Một. Email: utltk@tdmu.edu.vn.

DOI: $10.37550 /$ tdmu.CFR/2021.01.110

\section{Tóm tắt}

Thành lập Truờng trong bối cảnh giáo dục đại học Việt Nam bước vào thời kỳ đổi mới toàn diện để hội nhập quốc tế, trường đại học Thủ Dầu Một đã mạnh dạn thoát khỏi lối đi cũ mòn, tìm ra những khâu đột phá để làm nên sưc sống và tuơng lai của một truờng đại học. Một trong nhüng khâu đột phá quan trọng tạo nên điểm khác biệt cho Truờng chính là công tác xây dưng và cải tiến chương trình đào tạo. Chương trình đào tạo được thiết kế theo quan điểm giáo dục dưa trên kết quả, phuơng pháp tiếp cận theo CDIO, đáp úng chuẩn AUN-QA và lấy việc học làm trung tâm là kim chỉ nam để nhà trường xây dưng chuơng trình đào tạo đáp úng được yêu cầu của các bên liên quan và Chuẩn đầu ra mong đợi.

Tù̀ khóa: chuơng trình đào tạo, chuẩn đầu ra, cải tiến chuơng trình, CDIO, AUN-QA

\section{1. Đặt vấn đề}

Trường Đại học Thủ Dầu Một là cơ sở đào tạo đại học công lập của tỉnh Bình Dương, được thành lập năm 2009 trên cơ sở nâng cấp từ Trường Cao đẳng Sư phạm Bình Dương. Ngay từ buổi đầu xây dựng, Trường Đại học Thủ Dầu Một (Trường) đã xác định phương hướng chiến lược và quan điểm xây dựng trường đại học theo định hướng ứng dụng, gắn bó chặt chẽ với thực tiễn phát triển kinh tế, xã hội của tỉnh Bình Dương, các tỉnh miền Đông Nam Bộ - vùng kinh tế trọng điểm phía Nam, phù hợp với xu thế hội nhập quốc tế. Đến nay, Trường đã định hình là một cơ sở đại học đa ngành, đa lĩnh vực, phát triển cả về quy mô, chất lượng và hiệu quả đào tạo; đáp ứng nhu cầu học tập của người dân và yêu cầu công nghiệp hóa của địa phương và cả nước; bước đầu khẳng định uy tín và thương hiệu của một trường đại học mới trên đất Bình Dương. Được thành lập trong bối cảnh giáo dục đại học Việt Nam bước vào thời kỳ đổi mới toàn diện để hội nhập quốc tế, Trường đã mạnh dạn thoát khỏi lối đi cũ mòn, tìm ra những khâu đột phá để làm nên sức sống và tương lai của một trường đại học. Một trong những khâu đột phá quan trọng tạo nên điểm khác biệt cho Trường chính là công tác xây dựng chương trình đào tạo. Chương trình đào tạo được thiết kế theo quan điểm giáo dục dựa trên kết quả (Outcome based education, OBE), phương pháp tiếp cận theo CDIO đáp ứng chuẩn AUN-QA và lấy việc học làm trung tâm là 
kim chỉ nam để nhà trường xây dựng chương trình đào tạo đáp ứng được yêu cầu của các bên liên quan (người học, nhà tuyển dụng...) và Chuẩn đầu ra mong đợi.

\section{Xây dựng chương trình đào tạo tại Đại học Thủ Dầu Một}

\subsection{Quan điểm thiết kế chưong trình đào tạo}

Chương trình đào tạo của Nhà trường được thiết kế theo quan điểm giáo dục dựa trên kết quả, đảm bảo sự phát triển toàn diện cả kiến thức - kỹ năng - năng lực tự chủ và trách nhiệm cho người học thông qua kết quả học tập mong đợi. Kết quả học tập mong đợi phản ánh yêu cầu của các bên liên quan bên trong và bên ngoài, đáp ứng các yêu cầu của Khung trình độ quốc gia Việt Nam đối với đào tạo đại học và tương thích với các chương trình cùng ngành của các nước trong khu vực. Các hoạt động của chương trình bao gồm: Thiết kế, Phát triển, Triển khai, Đánh giá và Cải tiến chương trình. Toàn bộ các hoạt động này được vận hành theo đúng quy trình PDCA (Plan - Do - Check - Act), đảm bảo hoạt động đào tạo tại trường đáp ứng yêu cầu của các bên liên quan và Chuẩn đầu ra mong đợi.

Xác định công tác xây dựng Chuẩn đầu ra là một trong những khâu quan trọng trong chuỗi các hoạt động xây dựng chương trình đào tạo, bắt đầu từ năm 2012, Đại học Thủ Dầu Một đã mạnh dạn chuyển hướng xây dựng chương trình đào tạo theo đề xướng CDIO (Conceive - Design - Implement - Operate, nghĩa là: hình thành ý tưởng, thiết kế ý tưởng, thực hiện và vận hành), đáp ứng chuẩn AUN-QA (Asean University Network - Quality Assurance, nghĩa là: mạng luới các truờng đại học khu vục Đông Nam Á - đảm bảo chất luợng). Không chỉ thiết kế chương trình đào tạo theo đề xướng CDIO ở các khối ngành kỹ thuật, năm 2014, tất cả khối ngành đào tạo của Đại học Thủ Dầu Một (ĐHTDM) đã hoàn tất chương trình đào tạo theo đề xướng CDIO. Vì vậy, năm 2015, ĐHTDM đã trở thành thành viên của tổ chức $\mathrm{CDIO}$ thế giới. Đây là bước đi mạnh mẽ của Trường để khẳng định chất lượng đào tạo đối với xã hội. Không chỉ chú trọng thay đổi chương trình đào tạo cho phù hợp với xu thế thời đại, ĐHTDM còn tăng cường việc dạy kỹ năng xã hội, nâng cao chuẩn đầu ra về tin học, ngoại ngữ cho người học, đầu tư cơ sở vật chất... để đồng bộ việc nâng cao chất lượng, giúp người học khẳng định bản thân và có nhiều cơ hội việc làm sau khi tốt nghiệp đại học.

\subsection{Quá trình xây dụng chuơng trình đào tạo}

Đứng trước thách thức của nhu cầu xã hội, ĐHTDM luôn đề cao người học và đặt chất lượng đào tạo lên hàng đầu. Điều này lý giải vì sao hàng năm chương trình đào tạo luôn có sự cập nhật, bổ sung những học phần phù hợp thực tiễn, kèm theo các phiên bản mới của đề cương chi tiết. Nhất là vào năm 2017, sau khi đạt chuẩn kiểm định chất lượng giáo dục quốc gia, thông qua các buổi tổ chức DACUM (Developing a Curriculum - Phát triển chương trình đào tạo), từ ý kiến phản hồi của người sử dụng lao động, ĐHTDM đã tăng cường năng lực thực hành cho sinh viên trong quá trình học tập. Cơ sở đầu tiên cho quá trình cải tiến này là công văn số 30 ngày $5 / 01 / 2018$ của Hiệu trưởng trường ĐHTDM về việc chương trình đào tạo đại học chính quy khóa tuyển sinh 2017 và 2018, yêu cầu tất cả các ngành phải đảm bảo cơ cấu giờ thực hành tối thiểu đạt $40 \%$ trong khối lượng kiến thức toàn khóa (văn bản số 30 ngày 5/01/2018). Cải tiến chương trình đào tạo đối với khóa tuyển sinh 2020 theo hướng 2 giai đoạn, theo đó, Giai đoạn 1: sinh viên được trang bị kiến 
thức, kỹ năng, năng lực tự chủ và trách nhiệm, phương pháp học tập mang tính chất cơ sở ngành chung và liên ngành, xuyên ngành của nhóm chương trình đào tạo tương ứng; Giai đoạn 2: Sinh viên được trang bị những vấn đề lý thuyết, lý luận chuyên ngành, phương pháp, kỹ năng chuyên môn nghiệp vụ, thực tập/thực tế chuyên môn, thực tập tốt nghiệp phù hợp với chuyên ngành, làm khóa luận/báo cáo tốt nghiệp hoặc đồ án tốt nghiệp. Quá trình đào tạo được thực hiện theo quy trình: (1) dạy học lý thuyết; (2) dạy học trên mô hình, mô phỏng; (3) bài tập thực tế/thực hành, thực tập tại xưởng, phòng thí nghiệm; (4) bài tập ứng dụng/thực hành ngoài trường.

Với mong muốn nhằm tăng cường năng lực thực hành cho sinh viên và đạt chất lượng cao trong giảng dạy, việc thiết kế, xây dựng chương trình đào tạo đã "rải đều" giờ thực hành, thực tập trong suốt khóa học. Nghĩa là thực hiện từng bước: đầu tiên cho sinh viên làm quen với ngành nghề; sau là hiểu biết về nghề nghiệp; tiếp đến là đi thực tập tại cơ sở để vận dụng lý thuyết đã học vào nghề nghiệp; cuối cùng là vận hành, làm nghề. Vì vậy, để tránh việc sinh viên bỡ ngỡ khi tiếp xúc ngành nghề, từ năm học thứ nhất, qua học phần Nhập môn ngành, giảng viên tổ chức cho sinh viên được đi tham quan các cơ sở, doanh nghiệp... để làm quen với nghề nghiệp. Năm thứ hai, sinh viên được thực hành qua những mô hình, mô phỏng tại trường để có những hiểu biết nhất định cho nghề nghiệp trong tương lai. Việc thực hành được gắn liền với từng học phần trong chương trình đào tạo nhằm tạo bức tranh toàn cảnh về nghề nghiệp cho sinh viên. Đến năm thứ ba, sinh viên được đưa về cơ sở, doanh nghiệp... hoặc đi thực tế chuyên môn để thực tập nghề nghiệp. Tại đây, sinh viên vận dụng lý thuyết đã học vào thực tiễn dưới sự hướng dẫn của những người có tay nghề cao. Người học sẽ tích lũy kinh nghiệm, bổ sung những khiếm khuyết mắc phải, khắc phục những hạn chế để sang năm thứ tư đi thực tập sẽ vững vàng hơn, sẽ vận hành công việc như một người làm nghề thực thụ, từ đó tự tạo cho mình cơ hội tìm việc trong tương lai, đáp ứng yêu cầu của nhà tuyển dụng. Đó chính là "dây chuyền" hoạt động của quá trình đào tạo tại ĐHTDM và đảm bảo theo nguyên tắc từ đơn giản đến chuyên sâu; từ làm quen đến biết, hiểu, thực hành. Vì vậy, sinh viên dễ dàng tiếp cận tri thức; biết cách tự học và tích lũy kiến thức, kỹ năng để ứng dụng vào thực hành nghề nghiệp, góp phần nâng cao chất lượng đào tạo của Nhà trường.

Chương trình đào tạo được thiết kế phù hợp để vận hành thông suốt. Trong đó phải đảm bảo tính liên thông, liên ngành, nghĩa là chương trình đào tạo phải thể hiện tính mở, giúp sinh viên hiểu biết các kiến thức liên quan đến chuyên ngành và liên ngành. Qua đó, tạo cơ hội cho sinh viên được quyền chọn lại ngành nghề yêu thích sau khi học hết năm thứ nhất và thuận lợi trong việc đăng ký học các học phần cơ sở ngành. Điều này cũng đảm bảo được tính liên thông cho việc sinh viên có nguyện vọng học tập lên cao hơn nữa và có nhiều lựa chọn cho nghề nghiệp.

Không chỉ đảm bảo tính liên thông, liên ngành, chương trình đào tạo còn phải đảm bảo kiến thức, đảm bảo kỹ năng nghề nghiệp để đào tạo đội ngũ trí thức trẻ, có đủ năng lực, phẩm chất tự hoạt động sau khi ra trường. Điều này đòi hỏi khi thiết kế chương trình đào tạo, vừa phải chú ý khối lượng kiến thức, vừa phải đảm bảo kỹ năng nghề nghiệp cho sinh viên.

Để đảm bảo mối liên kết chuẩn đầu ra với với các hoạt động dạy - học và kiểm tra đánh giá theo nguyên lý dựa trên $\mathrm{OBE}$, việc thay đổi phương pháp giảng dạy phù hợp để chuyển tải các kiến thức một cách hiệu quả để sinh viên vận dụng trong học tập, nhất là việc thực hành, thực tập là quan trọng, vì vậy, phương pháp giảng dạy theo hướng hòa hợp, tích cực, lấy người 
học làm trung tâm đã ra đời. Sự ra đời của phương pháp này đã kịp thời chuyển tải những thông điệp mà giảng viên muốn truyền đạt đến sinh viên. Những thông điệp mà chuẩn đầu ra phải phù hợp với mục tiêu đào tạo và nhu cầu của người sử dụng lao động.

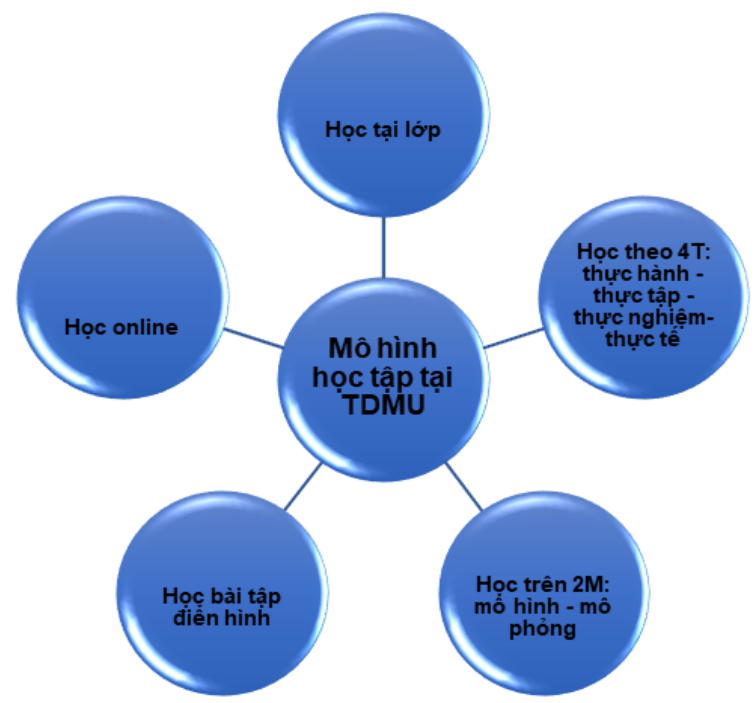

\section{Hình 1. Mô hình học tập tại Trường Đại học Thủ Dầu Một}

Phương pháp dạy học và đánh giá theo quan điểm lấy người học làm trung tâm đóng vai trò quan trọng trong việc thực hiện triết lý giáo dục của nhà trường để tạo ra động cơ học tập, sự suy ngẫm và sự chủ động trong học tập của sinh viên. Chương trình của Trường dựa trên quan điểm lấy sinh viên (SV) làm trung tâm khi thiết kế và triển khai dạy và học cũng như đánh giá $\mathrm{SV}$. Chương trình của $\mathrm{ĐHTDM}$ được giảng dạy bằng các phương pháp khuyến khích $\mathrm{SV}$ đóng vai trò chủ động trong việc tạo ra quá trình học tập, linh hoạt trong các phương pháp giảng dạy, đồng thời xây dựng Hệ thống quản lý học tập (LMS - Learning Management System) giúp hỗ trợ các công tác quản lý giáo dục, bài giảng, phân phối các tài liệu học tập đến người học đạt hiệu quả cao. Toàn bộ bài giảng, kiến thức được truyền tải đến người học thông qua nhiều phương tiện tiện ích giúp người học tiếp thu kiến thức tốt hơn. Nhà Trường xây dựng hệ thống hồ sơ điện tử E-Portfolio cho giảng viên và sinh viên đang học tập và công tác tại trường. Hệ thống này giúp sinh viên trường có thể lưu trữ được toàn bộ dữ liệu quá trình học tập, chủ động trong việc lên kế hoạch học tập cá nhân, các tài liệu, kết quả học tập là cơ sở cho việc việc đánh giá tiến độ kiến thức, kỹ năng, năng lực tự chủ và trách nhiệm của người học. Đồng thời thông qua hệ thống này, toàn bộ kết quả học tập được thể hiện cụ thể, thuyết phục được nhà tuyển dụng bởi những minh chứng về các hoạt động, tài liệu học tập, nghiên cứu... là kết quả mà sinh viên tạo trong quá trình học tập. Bên cạnh đó, hệ thống E.Portfolio giúp giảng viên theo dõi, nhắc nhở tiến độ học tập của sinh viên, từ đó đánh giá được những kiến thức, kỹ năng sinh viên tích lũy được và đưa ra những ý kiến tư vấn, hỗ trợ kịp thời cho sinh viên trong học tập. Đồng thời, những tri thức mới được chuyển tải vào các học phần, các hoạt động khảo cứu, project ứng dụng và nghiên cứu khoa học của sinh viên cũng được đưa vào hệ thống E.Portfolio để tạo một hồ sơ hoàn chỉnh cho người học. Thông qua hệ thống E.Portfolio, giảng viên áp dụng các phương pháp đánh giá sinh viên nhằm mục đích cung cấp cơ hội đa dạng cho người học thể hiện việc đạt được kết quả học tập mong đợi của chương trình đào tạo và kết quả đánh giá này được thực hiện một cách chính xác và công bằng đối với người học. Bên cạnh đó, 
các hoạt động học tập trải nghiệm, học tập phục vụ cộng đồng cũng được nối kết chặt chẽ với hoạt động dạy và học, giúp SV nâng cao chất lượng học tập kiến thức, kỹ năng cũng như năng lực tự chủ, ý thức trách nhiệm xã hội và các giá trị đạo đức. Từ đó, giúp người học có đủ kiến thức và sự tự tin để học tập suốt đời và nâng cao trình độ của bản thân.

\subsection{Thành tưu về công tác xây dụng chương trình đào tạo của nhà trưòng}

Từ khi xây dựng chương trình đến vận hành, thực hiện đào tạo, trường ĐHTDM luôn đặt chất lượng lên mục tiêu hàng đầu. Vì vậy, chương trình đào tạo được cập nhật, cải tiến thường xuyên để đáp ứng nhu cầu xã hội. Đó cũng là câu trả lời của Nhà trường trong việc đảm bảo chuẩn đầu ra mong đợi: người học có thể tự đào tạo và có kỹ năng học tập suốt đời. Điều này được thể hiện qua sự phát triển về số lượng chương trình đào tạo đại học, cao học, nghiên cứu sinh từ năm 2009 đến nay của trường (hình 2).

Việc xây dựng, phát triển chương trình đào tạo đã giúp hoạt động đào tạo của Nhà trường ngày càng đi vào chiều sâu và nâng tầm chất lượng. Kết quả đó được công nhận qua việc đánh giá chất lượng giáo dục từ trong nước đến khu vực (hình 3).

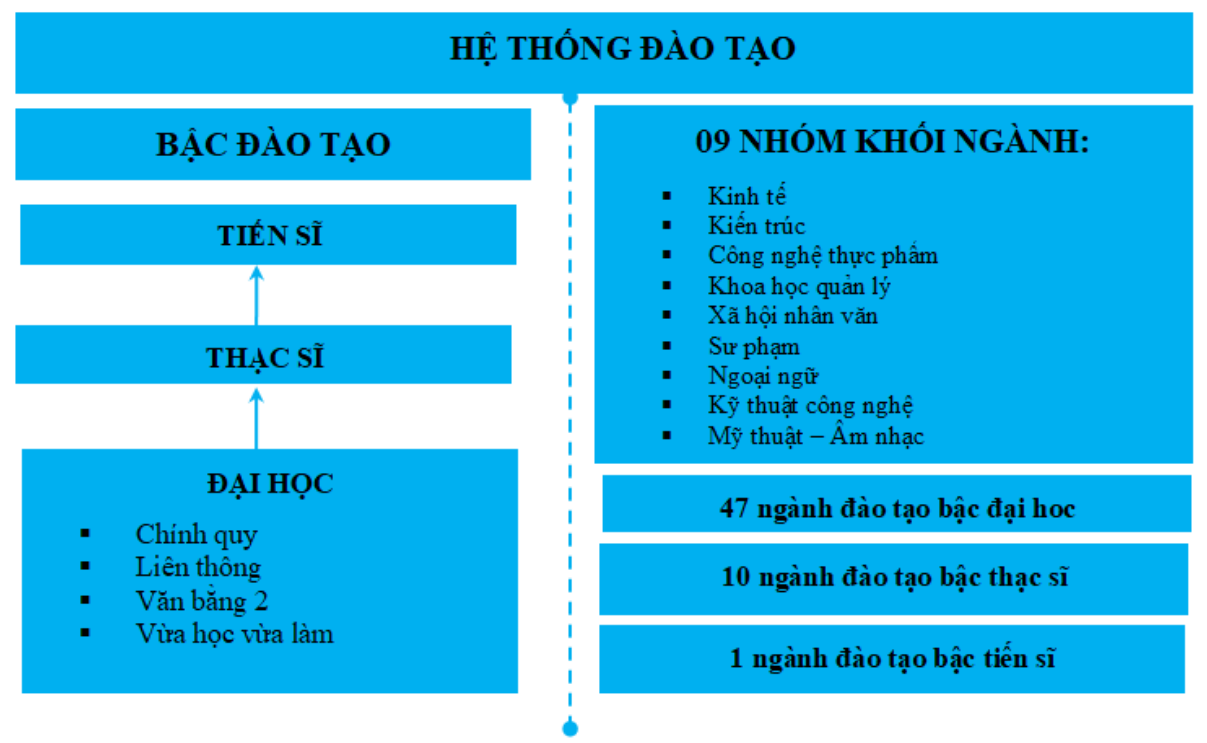

Hình 2. Thành tưu các bậc đào tạo của truờng tù 2009-2020

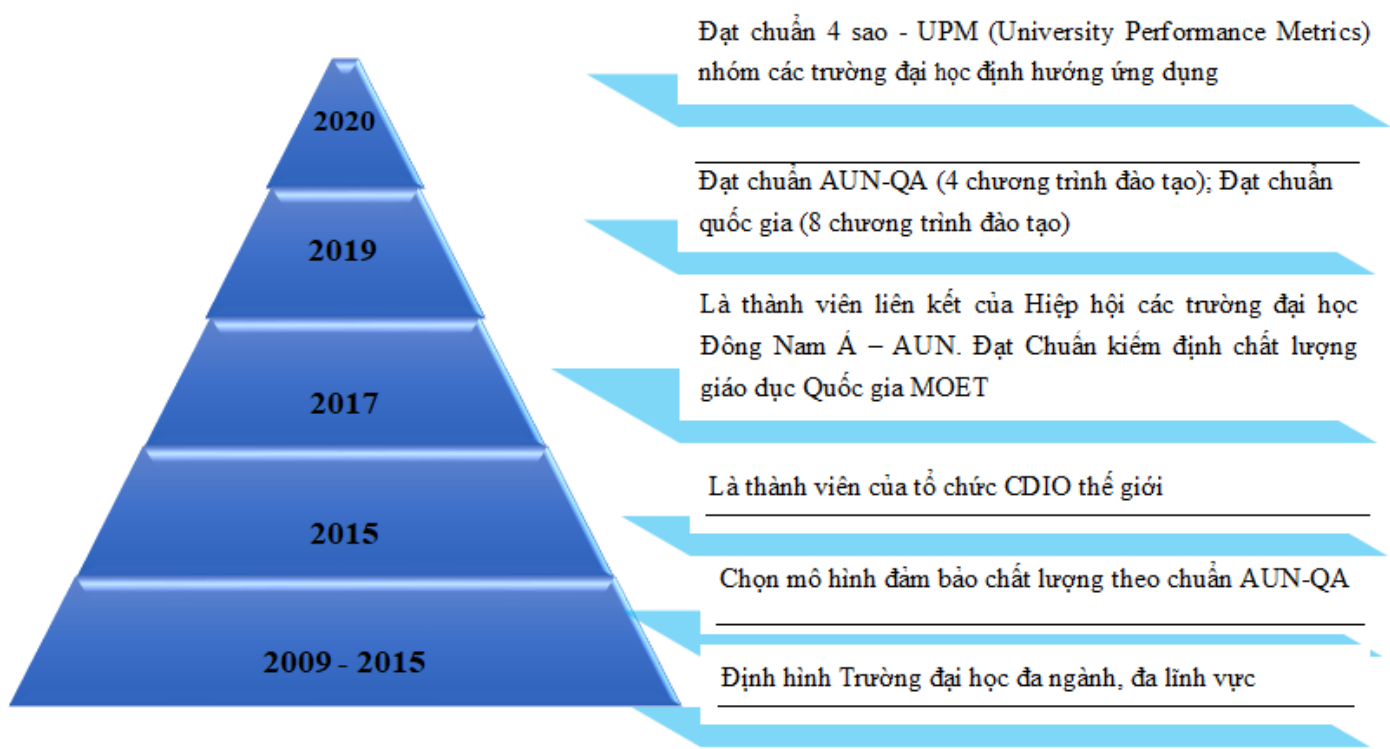


Hình 3. Kết quả hoạt động của nhà truờng qua 10 năm (tù̀ 2009-2020)

\section{Kết luận}

Với sự phát triển của khoa học kỹ thuật hiện nay, giáo dục không thể đào tạo ra những con người chỉ biết làm một việc, chỉ biết vận hành công việc như một chú robot. Trách nhiệm của Nhà trường trong quá trình đào tạo là phải chú trọng đến việc đào tạo kỹ năng nghề nghiệp để người học có đủ hành trang khi bắt tay vào công việc trong thực tiễn, đồng thời tránh việc nhà tuyển dụng phải đào tạo lại. Việc đào tạo kỹ năng nghề nghiệp cũng phải dần được nâng tầm quốc tế, nhằm trang bị cho sinh viên có đủ các yếu tố về kiến thức, kỹ năng, ngoại ngữ, tin học... để làm việc ở nước ngoài và hội nhập với khu vực.

Làm thế nào để đạt được mục tiêu và đáp ứng chuẩn đầu ra theo yêu cầu của xã hội? Để giúp sinh viên có phương pháp học tập phù hợp, đồng thời tích lũy kiến thức và kinh nghiệm ngay từ khi còn ngồi trên ghế nhà trường, trong quá trình đào tạo, Đại học Thủ Dầu Một luôn hướng đến việc đảm bảo năng lực đáp ứng nhu cầu xã hội, và việc thiết kế, xây dựng chương trình là một trong những khâu quan trọng trong chuỗi đào tạo của trường. Nhận thấy được tầm quan trọng của việc thiết kế, xây dựng chương trình đào tạo có sự ảnh hưởng to lớn đến chất lượng đào tạo nên Trường ĐHTDM đã có quan điểm rõ ràng ngay từ lúc bắt đầu xây dựng chương trình đào tạo. Sự dứt khoát, mạnh mẽ đó đã làm bệ phóng cho công tác xây dựng chương trình đào tạo tại ĐHTDM được thuận lợi và mang lại hiệu quả cao, góp phần vào thành tích chung của Trường trong 10 năm qua.

\section{Tài liệu tham khảo}

[1] Công văn số 30/ĐHTDM-ĐTĐH ngày 5 tháng 1 năm 2018 của Hiệu trưởng trường đại học Thủ Dầu Một về Chương trình đào tạo đại học chính quy khóa tuyển sinh 2017 và 2018.

[2] Công văn số 204/ĐHTDM-ĐTĐH ngày 6 tháng 5 năm 2020 của Hiệu trưởng trường đại học Thủ Dầu Một về Xây dựng Chương trình đào tạo đại học chính quy 2 giai đoạn khóa tuyển sinh 2020.

[3] Công văn số 204/ĐHTDM-ĐTĐH ngày 6 tháng 5 năm 2020 của Hiệu trưởng trường đại học Thủ Dầu Một về Xây dựng Chương trình đào tạo đại học chính quy 2 giai đoạn khóa tuyển sinh 2020.

[4] Nghị quyết số 05/NQ-HĐTr ngày 22 tháng 06 năm 2018 của Hội đồng trường về Thông qua chiến lược phát triển Trường Đại học Thủ Dầu Một đến năm 2030.

[5] Đoàn Thị Minh Trinh, Nguyễn Quốc Chính, Nguyễn Hữu Lộc, Phạm Công Bằng, Peter J. Gray, Hồ Tấn Nhựt (2012), Thiết kế và phát triển chương trình đào tạo đáp ứng chuẩn đầu $\mathrm{ra}, \mathrm{Nxb}$. Đại học quốc gia thành phố Hồ Chí Minh.

[6] Đoàn Thị Minh Trinh, Nguyễn Hội Nghĩa (2014), Hướng dẫn thiết kế và phát triển chương trình đào tạo đáp ứng chuẩn đầu ra, Nxb. Đại học quốc gia thành phố Hồ Chí Minh. 